\title{
Regulate alcohol for global health
}

\section{The World Health Organization is the only body that can promote health through the use of international law. It should make alcohol its next target, says Devi Sridhar.}

$\mathrm{U}$ nlike any other global-health body, the World Health Organization (WHO) can create legally binding conventions, and it only requires a twothirds majority vote to do so. Yet this power is vastly underused. In more than 60 years, this United Nations agency has produced only two major treaties: the International Health Regulations, which require countries to report certain disease outbreaks and public-health events; and the Framework Convention on Tobacco Control, which commits governments to making legislative moves to reduce the demand for, and supply of, tobacco. The WHO has shown a reluctance to use hard legal instruments. Instead, it tries to influence societal norms through guidelines and recommendations $s^{1}$. This is a major missed opportunity.

Now is the time for the WHO to take a bold step and move towards a third treaty to protect world health. There is an obvious target. About 2.5 million deaths a year, almost $4 \%$ of all deaths worldwide, are attributed to alcohol - more than the number of deaths caused by HIV/AIDS, tuberculosis or malaria ${ }^{2}$. Alcohol consumption is the world's third-largest risk factor for health burden; in middle-income countries, which constitute almost half of the world's population, it is the greatest risk (see 'Health burdens').

There are some good, evidencebased efforts for alcohol control already in place, such as the 2010 WHO Global Strategy to Reduce Harmful Use of Alcohol. This document lays out ten areas in which action can be taken, from raising awareness to preventing drink-driving and restricting the availability, marketing and pricing of alcohol. Its recommended policy interventions are general and sensible, including: banning unlimited drinks specials; enforcing a reasonable minimum age limit for purchase; and enacting graduated licensing for novice drivers with zero-tolerance for drinkdriving. The strategy helpfully summarizes the cost-effectiveness of various strategies. But this is a portfolio of useful information and policy tips, not a binding document.

A WHO Framework Convention on Alcohol Control could and should turn those recommendations into legal requirements for member states. What difference would this make? Formally, countries would commit to applying the agreement through national legislation - which would require a ream of new policies for nations such as India where current regulation isn't so comprehensive. Nations would be required to report to the WHO on their progress. The international community would have a shared responsibility to support these efforts by providing financial and technical assistance as needed. Informally, ministries of health would have a stronger domestic negotiating position in prioritizing alcohol regulation above economic concerns.

\section{HEALTH BURDENS}

Alcohol is the third-largest risk factor for loss of years to disease and disability. The effect is largest in middle-income countries (2004 data).

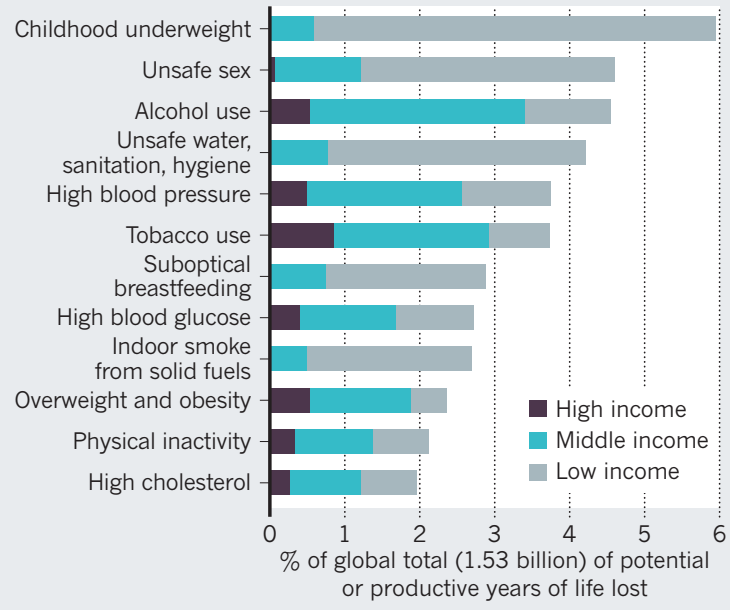

Non-governmental organizations would be able to pressure governments, and even bring issues to court.

The creation of a framework convention requires much political work and preparation. The WHO secretariat should, for example, map out the positions of countries on alcohol use, their links to industry, and how best to overcome opposition in each nation. Doing so will require donor funding for a special cabinet project, as was done for tobacco. The overarching goal would be to assemble a 'coalition of the willing and able' to push this agenda forward in the World Health Assembly - the WHO's decisionmaking body.

We should not be overly idealistic about the effect of international health law on

\section{SNATURE.COM} The WHO needs to be reformed: go.nature.com/snx4vp domestic public health. Despite a binding Framework Convention on Tobacco Control, tobacco use is increasing in many poor countries, and is still the second-largest cause of disease risk in middle-income countries. The problem is that oversight is minimal and no strong enforcement mechanisms exist, so compliance is weak.

\section{STRENGTHENED POWERS}

To help overcome such problems, the WHO should endorse a commission on global health law, headed by an independent expert. Through analysis of other regimes, such as those of trade and finance, that have arguably been more successful in utilizing international law, this commission could provide recommendations on how to strengthen the WHO's normative power.

The WHO's legal potential should not be focused solely on individual health hazards such as alcohol and tobacco, it should be used to create a broad framework convention on global health ${ }^{3}$. This would identify a basic package of health services that governments ought to provide; identify who would be obliged to provide what; and examine how this could be achieved through reform of global health governance.

To flourish in an environment with numerous other better-financed and more-inclusive institutions, the WHO must take a hard look at itself and what makes it special. Other bodies can provide technical advice, give money, influence domestic health policy, assist in development and advocate for the importance of health in government policy. The WHO is the only body with the legitimacy and authority to proactively promote health through the use of international law. It needs to do so.

Devi Sridhar is in the Department of Public Health and the George Centre for Healthcare Innovation, Wolfson College, University of Oxford, Oxford OX2 6UD, UK. e-mail:devi.sridhar@dph.ox.ac.uk

1. L'hirondel, A. \& Yach, D. World Health Stat. Q. 51, 79-87 (1998).

2. World Health Organization. Global Status Report on Alcohol and Health 2011 (WHO, 2011); available at http://go.nature.com/ymav6z

3. Gostin, L. O. et al. PLoS Med 8, e1001031 (2011). 